\title{
Role of Tractional Forces and Internal Limiting Membrane in Macular Hole Formation: Insights from Intraoperative Optical Coherence Tomography
}

\author{
Elad Moisseiev Glenn Yiu \\ UC Davis Eye Center, University of California Davis, Sacramento, Calif., USA
}

\section{Keywords}

Optical coherence tomography · Vitreomacular traction · Macular hole $\cdot$ Internal limiting membrane

\begin{abstract}
We report the case of a 69-year-old patient who underwent vitrectomy for vitreomacular traction (VMT) and developed a postoperative macular hole that was observed 1 week after surgery. The hole did not close by in-office fluid-gas exchange alone, but was achieved after repeat surgery with internal limiting membrane (ILM) peeling. Intraoperative OCT (iOCT) images from the first surgery revealed an occult macular hole that formed after VMT release. We discuss how IOCT findings provide insight into the role of the ILM in macular hole formation and emphasize the importance of carefully inspecting $\mathrm{IOCT}$ images in real time to avoid missing small but important findings.

(c) 2016 The Author(s)

Published by S. Karger AG, Basel
\end{abstract}

\section{Introduction}

A combination of tangential and antero-posterior traction has been postulated in the pathogenesis of macular hole (MH) formation resulting from vitreomacular traction (VMT) 


\section{Case Reports in Ophthalmology}

[1]. Treatment with intravitreal ocriplasmin (Jetrea; Thrombogenics, Iselin, N.J., USA) can relieve antero-posterior traction and results in $\mathrm{MH}$ closure in $40 \%$ of cases [2]. However, removal of tangential forces by internal limiting membrane (ILM) peeling has also been shown to improve MH closure after vitrectomy [3]. The balance of these forces is wellillustrated in the case that we present here, where intraoperative optical coherence tomography (iOCT) during vitrectomy for an eye with VMT revealed a small retinal defect that rapidly enlarged to a large full-thickness $\mathrm{MH}$ over 1 week. The $\mathrm{MH}$ remained open after treatment with gas tamponade alone, but closed after the ILM peeling was performed.

\section{Case Report}

A 69-year-old woman presented for evaluation of VMT in her left eye. Her history included high myopia and pseudophakia in both eyes and prior laser retinopexy for a retinal tear in the affected eye. On examination, VA was 20/30 in the right eye and 20/50 in the left eye. Pupils were normal with no relative afferent pupillary defect and the intraocular pressures were normal. Anterior segments were normal in both eyes, and dilated fundus examination was normal in the right eye. Spectral domain OCT (SD-OCT; Heidelberg Spectralis) demonstrated VMT with an inner lamellar hole (fig. 1a). The patient desired treatment for her worsening vision and metamorphopsia, and surgical repair was recommended.

A 25-gauge pars plana vitrectomy was performed, and the adherent posterior hyaloid required use of intravitreal triamcinolone and an illuminated pick to carefully induce a posterior vitreous detachment. iOCT imaging (Zeiss Rescan 700) demonstrated successful release of the VMT from the posterior pole (fig. 2a, b), and no ILM peeling or gas tamponade was performed. On the first postoperative day, VA was 20/60, but it decreased to 20/200 at 1 week. A full-thickness MH of approximately $500 \mu \mathrm{m}$ in diameter was noted (fig. 1b). The patient underwent in-office fluid-gas exchange with 16\% C3F8, followed by face-down positioning. One week later, her VA had not improved and the MH remained open (fig. 1c). She then underwent 25-gauge vitrectomy with ILM peeling and 20\% SF6 gas, following which the $\mathrm{MH}$ closed (fig. 1d). A closer retrospective review of the iOCT scans obtained during her first surgery revealed an occult full-thickness MH after lifting the posterior hyaloid (fig. 2c). The retinal defect was only seen in a single scan from numerous scans of the macular region, and was not noticed during the surgery. The patient was followed for 8 months after surgery with no additional complications. Her final VA was 20/100.

\section{Discussion}

MH formation is an uncommon complication of vitrectomy surgery for VMT [4], but its occurrence may recapitulate the mechanism by which spontaneous VMT release can lead to idiopathic MH formation. Here, iOCT imaging showed a small retinal defect during surgery that rapidly enlarged to a 500- $\mu \mathrm{m}$ MH over 1 week, which could only be closed subsequently with ILM peeling, suggesting that significant tangential traction from the ILM was present. We postulate that this tangential traction was unmasked after the antero-posterior traction and centripetal forces were relieved from VMT release in the initial surgery, and the tangential forces were left unopposed to cause the large $\mathrm{MH}$.

This case supports the important role of the ILM in the pathophysiology of MHs, and that ILM peeling may not just be a surrogate for removing vitreous cortex remnants at the 
Moisseiev and Yiu: Role of Tractional Forces and Internal Limiting Membrane in Macular Hole Formation: Insights from Intraoperative Optical Coherence Tomography

macula which may contract and induce $\mathrm{MH}$ formation or prevent hole closure [5]. Here, iOCT imaging showed no evidence of residual vitreous, and MH closure was only achieved after ILM removal. Importantly, this case also demonstrates the strengths and weaknesses of current intrasurgical imaging technologies. iOCT may reveal subclinical changes that impact surgical decision-making [6] as well as changes in the retinal architecture caused by the surgical instrumentation [7]. However, cursory intraoperative review of these images and the limited quality of heads-up display projections may also lead to a false sense of security if subtle changes are overlooked. Hence, while iOCT is a useful emerging adjunct for vitreoretinal surgery, clinical judgment remains paramount.

\section{Statement of Ethics}

The patient described has given informed consent for this publication.

\section{Disclosure Statement}

No author has any proprietary interest in the publication of this report.

\section{References}

1 Gaudric A, Haouchine B, Massin P, Paques M, Blain P, Erginay A: Macular hole formation: new data provided by optical coherence tomography. Arch Ophthalmol 1999;117:744-751.

-2 Stalmans P, Benz MS, Gandorfer A, Kampik A, Girach A, Pakola S, Haller JA; MIVI-TRUST Study Group: Enzymatic vitreolysis with ocriplasmin for vitreomacular traction and macular holes. New Engl J Med 2012;367:606-615.

-3 Spiteri Cornish K, Lois N, Scott NW, Burr J, Cook J, Boachie C, Tadayoni R, la Cour M, Christensen U, Kwok AK: Vitrectomy with internal limiting membrane peeling versus no peeling for idiopathic fullthickness macular hole. Ophthalmology 2014;121:649-655.

-4 Gonzalez MA, Flynn HW Jr, Bokman CM, Feuer W, Smiddy WE: Outcomes of pars plana vitrectomy for patients with vitreomacular traction. Ophthalmic Surg Lasers Imag Retina 2015;46:708-714.

-5 Kimura H, Kuroda S, Nagata M: Macular hole formation in postvitrectomized eyes. Retina 2005;25:521523.

6 Ehlers JP, Tam T, Kaiser PK, Martin DF, Smith GM, Srivastava SK: Utility of intraoperative optical coherence tomography during vitrectomy surgery for vitreomacular traction syndrome. Retina 2014;34:1341-1346.

7 Ehlers JP, Han J, Petkovsek D, Kaiser PK, Singh RP, Srivastava SK: Membrane peeling-induced retinal alterations on intraoperative OCT in vitreomacular interface disorders from the PIONEER study. Invest Ophthalmol Vis Sci 2015;56:7324-7330. 


\section{Case Reports in Ophthalmology}

\begin{tabular}{l|l}
\hline Case Rep Ophthalmol 2016;7:372-376 \\
\hline $10.1159 / 000446980$ & $\begin{array}{l}\text { ○ } 2016 \text { The Author(s). Published by S. Karger AG, Basel } \\
\text { www.karger.com/cop }\end{array}$ \\
\hline
\end{tabular}

Moisseiev and Yiu: Role of Tractional Forces and Internal Limiting Membrane in Macular Hole Formation: Insights from Intraoperative Optical Coherence Tomography
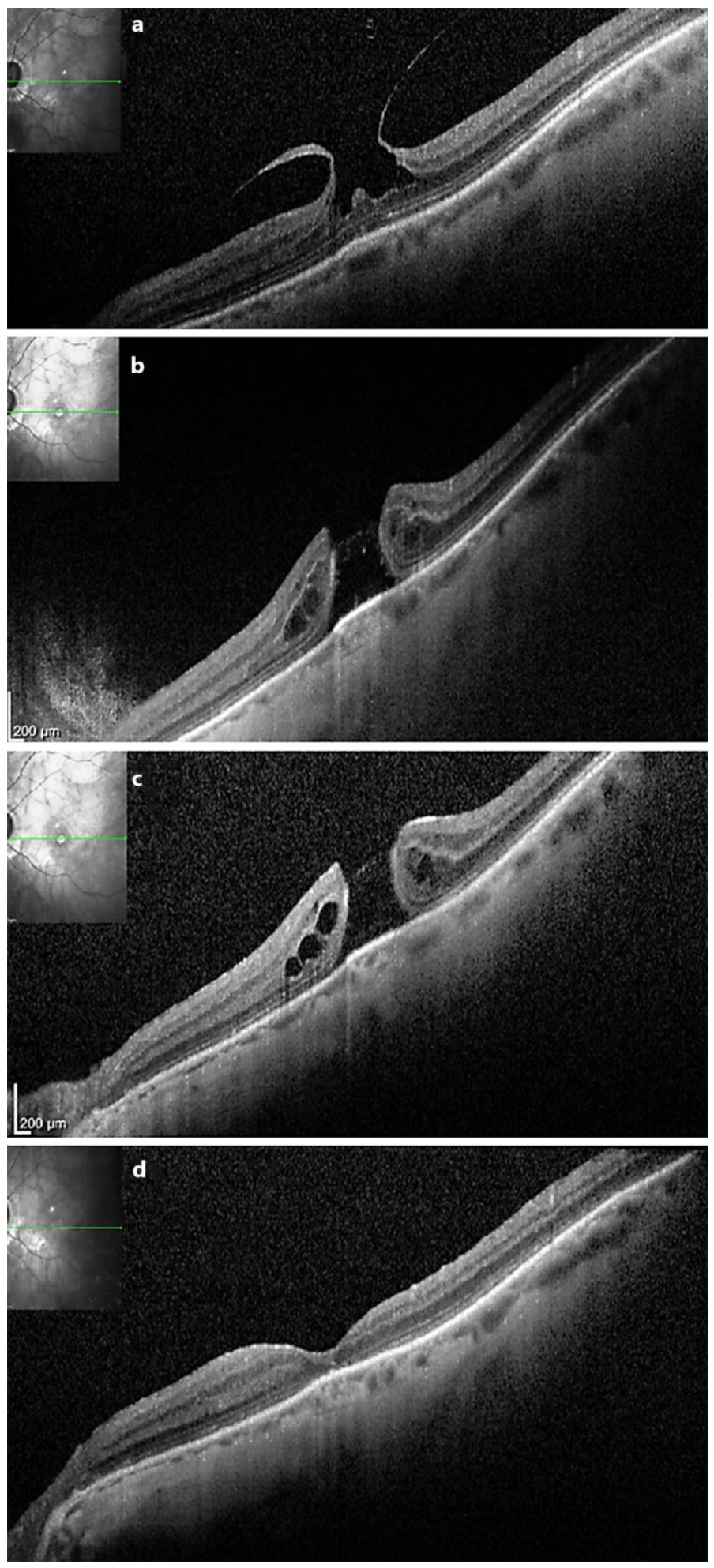

Fig. 1. SD-OCT images reveal VMT with a lamellar hole in the left eye prior to surgery (a). One week after initial surgery, a full-thickness MH was noted (b). The MH remained open 1 week following a fluid-gas exchange procedure (c). Following vitrectomy with ILM peeling and gas tamponade, the hole closed, with some outer retinal layer disruption (d). 


\section{Case Reports in Ophthalmology}
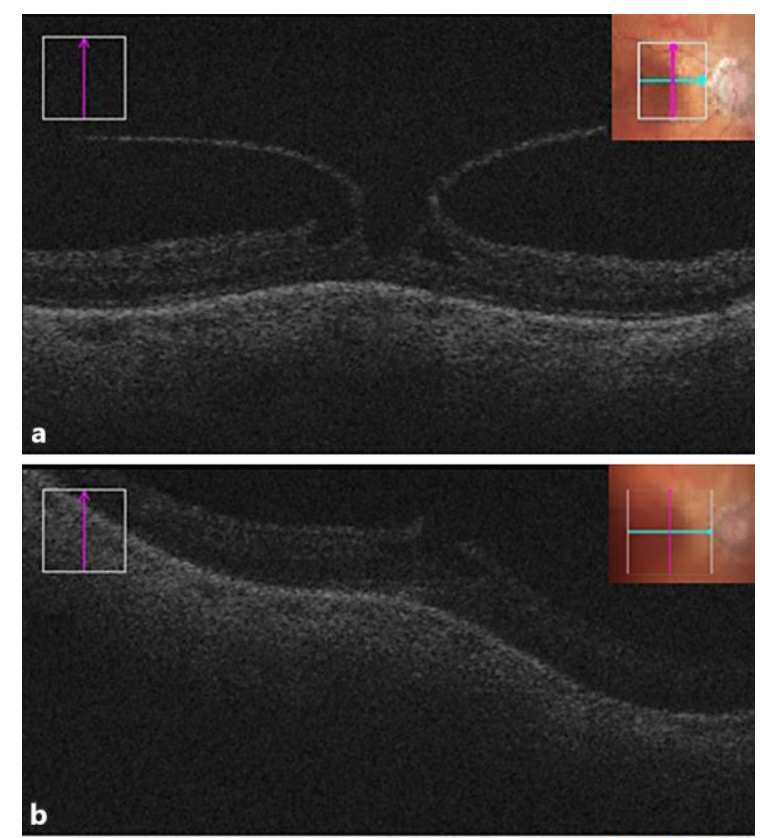

b
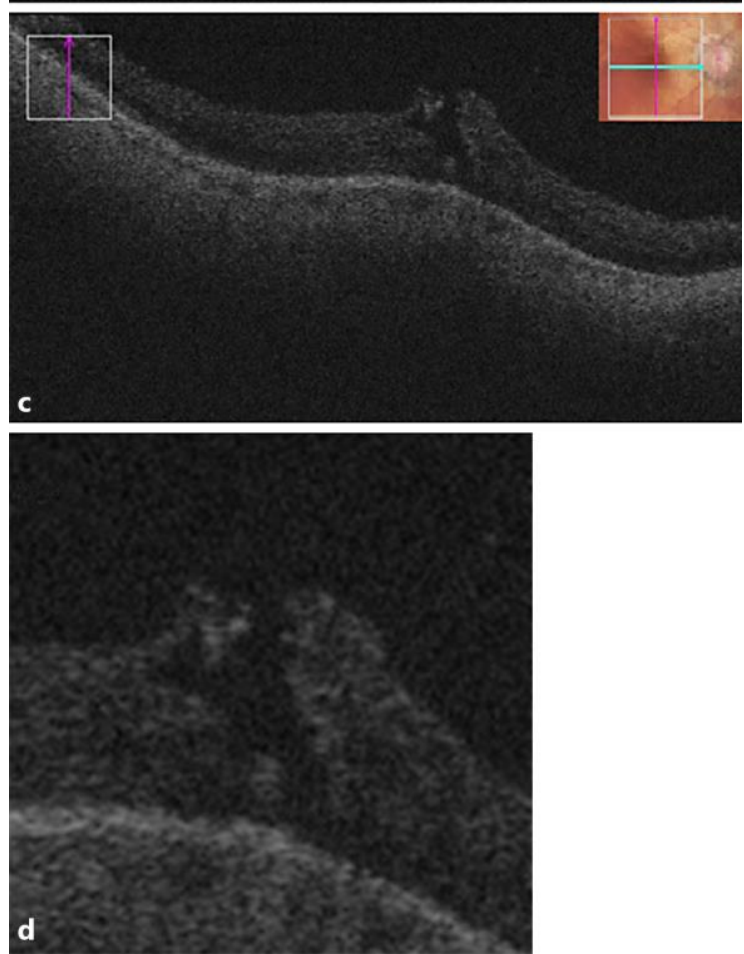

Fig. 2. iOCT images show VMT and lamellar hole prior to vitrectomy (a). Following vitrectomy and lifting the posterior hyaloid, the VMT was effectively released, with persistence of the lamellar hole (b). Upon further review, one iOCT image demonstrated an occult full-thickness MH (c). In $\mathbf{d}$ an enlarged view is shown. 